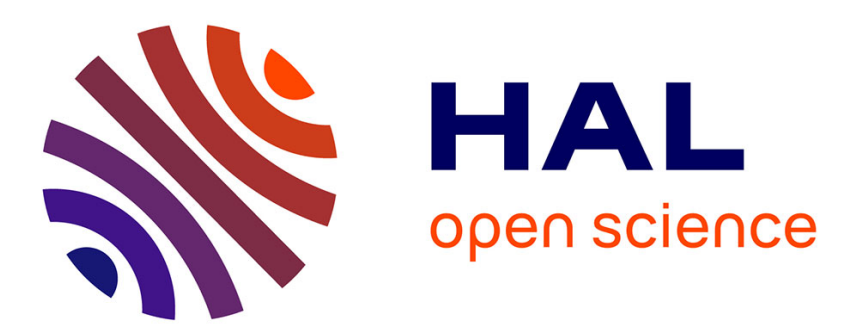

\title{
Synthesis of oxy-hydroxyfluorinated anatase nanoparticles grown on carbon nanotubes
}

Wei Li, Encarnación Raymundo-Piñero, Olaf J. Borkiewicz, Henri Groult, Damien Dambournet

\section{- To cite this version:}

Wei Li, Encarnación Raymundo-Piñero, Olaf J. Borkiewicz, Henri Groult, Damien Dambournet. Synthesis of oxy-hydroxyfluorinated anatase nanoparticles grown on carbon nanotubes. Journal of Fluorine Chemistry, 2018, 215, pp.32-35. 10.1016/j.jfluchem.2018.09.003 . hal-01957400

\section{HAL Id: hal-01957400 \\ https: / hal.sorbonne-universite.fr/hal-01957400}

Submitted on 17 Dec 2018

HAL is a multi-disciplinary open access archive for the deposit and dissemination of scientific research documents, whether they are published or not. The documents may come from teaching and research institutions in France or abroad, or from public or private research centers.
L'archive ouverte pluridisciplinaire HAL, est destinée au dépôt et à la diffusion de documents scientifiques de niveau recherche, publiés ou non, émanant des établissements d'enseignement et de recherche français ou étrangers, des laboratoires publics ou privés. 


\section{Synthesis of oxy-hydroxyfluorinated Anatase Nanoparticles Grown on Carbon Nanotubes}

Wei $\mathrm{Li}^{\mathrm{a}}$, Encarnación Raymundo-Piñero ${ }^{\mathrm{b}, \mathrm{d}}$, Olaf J. Borkiewicz ${ }^{\mathrm{c}}$, Henri Groult ${ }^{\mathrm{a}, \mathrm{d}}$, Damien Dambournet ${ }^{\mathrm{a}, \mathrm{d}^{*}}$

${ }^{a}$ Sorbonne Université, CNRS, Physico-chimie des électrolytes et nano-systèmes interfaciaux, PHENIX, F-75005 Paris, France

${ }^{\mathrm{b}}$ CEMHTI - CNRS Orléans, site haute température, 1D Avenue de la Recherche Scientifique, 45071 Orléans Cedex 02, France

${ }^{c}$ X-ray Science Division, Advanced Photon Source, Argonne National Laboratory, Argonne, Illinois 60439, USA

${ }^{\mathrm{d}}$ Réseau sur le Stockage Electrochimique de I'Energie (RS2E), FR CNRS 3459, 80039 Amiens cedex, France

Corresponding author: damien.dambournet@sorbonne-universite.fr

Graphical abstract:

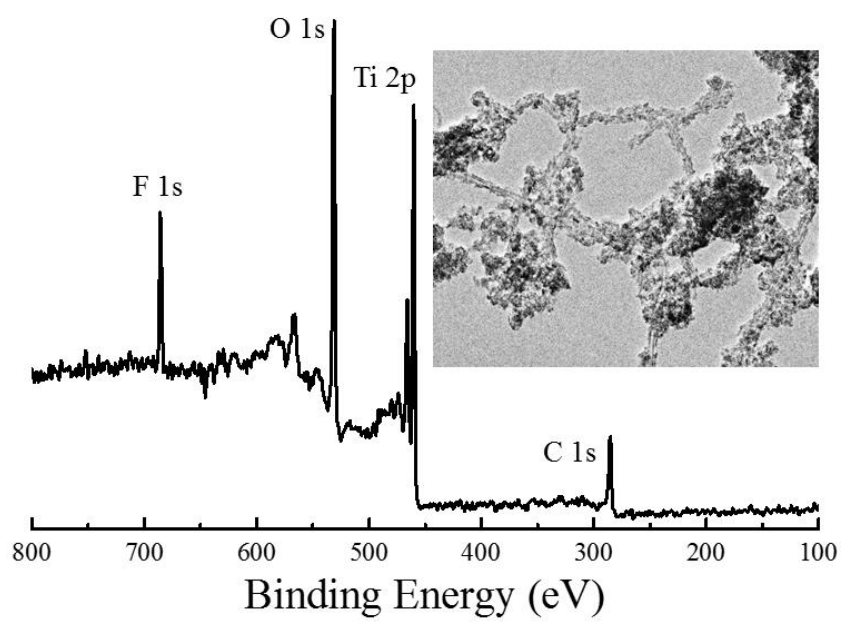

Highlights:

- Fluorolysis of titanium isopropoxide in the presence of carbon nanotubes

- Synthesis of composite materials made of carbon nanotube and a titanium oxyhydroxyfluoride compound

- Role of the surface functionalization of CNTs on the growth of nanoparticles 
Abstract: The synthesis of composite materials containing carbon nanotubes (CNTs) and inorganic nanocrystals is of interest to combine the specific properties of each components. While literature provides broad studies on the growth of anatase $\mathrm{TiO}_{2}$ onto CNTs, it has never been reported how the presence of aqueous HF could affect the chemical composition of CNTs. Here, we demonstrated that CNTs are inactive toward fluorination during the solvothermal synthesis of an oxy-hydroxyfluorinated compound featuring the anatase-type structure. We further showed that functionalized CNTs offer nucleation sites that favor nanocrystals growth. As a result, the prepared composite features CNTs that are decorated by anatase nanocrystals. The results also showed that, in this condition, titanium alkoxide readily react with HF via a fluorolysis reaction allowing stabilizing high content of fluorine within the anatase network.

Keywords: sol-gel, fluorolysis, composite materials, carbon nanotubes, inorganic nanocrystals.

\section{Introduction}

Sol-gel chemistry relies on the condensation of molecular precursors formed through the reactivity of metal-alkoxide bonds.[1] In 2003, Kemnitz and colleagues were the first to investigate the reactivity of of metal-alkoxide bonds toward anhydrous HF proposing to name the following reaction M-OR $+\mathrm{HF}$ $\rightarrow \mathrm{M}-\mathrm{F}+\mathrm{R}-\mathrm{OH}$, fluorolysis by analogy with hydrolysis.[2,3]

The reaction system employing titanium alkoxide with aqueous HF treated under solvothermal conditions was initially used to promote the growth of (001)-faceted nanoparticles of anatase $\mathrm{TiO}_{2}$.[4] In 2015, using a low temperature, we showed that fluoride and hydroxide were partially substituting oxide inducing a charge-compensating titanium vacancy $(\square)$ such as $\mathrm{Ti}_{1-x-y} \square_{x+y} \mathrm{O}_{2-4(x+y)} F_{4 x}(O H)_{4 y}$. [5] Subsequently, we investigated its formation mechanism revealing a solid-state transformation of a highly defective anatase phase having a hydroxyfluoride composition which further evolves through oxolation reaction into an oxy-hydroxyfluoride phase.[6] It further shows that titanium alkoxide precursors can react with HF via a fluorolysis process.

The combination of inorganic compounds with electronic conductors such as carbon nanotubes (CNTs) have been widely employed to prepare composite materials with unique properties in numerous fields such as photocatalysis[7,8] and energy storage[9]. Numerous methods have been used to prepare CNTs-based nanocomposites.[10] Sol-gel process is effective to grow inorganic nanocrystal onto CNTs.[8] The presence of HF, however, might alter the reactivity and crystal growth of the nanoparticles onto the CNTS. In this work, we investigated the feasibility of growing anatase onto 
CNTs in a fluorinating medium which could open new opportunities in the fields of energy storage and conversion. $[11,12]$

\section{Results and discussion}

For the synthesis, CNTs and titanium isopropoxide were first mixed together in a solution of isopropanol (see experimental section). Thereafter a solution of aqueous HF diluted in isopropanol was added. The resulting mixed solution was heated treated under solvothermal conditions at $90{ }^{\circ} \mathrm{C}$ for $12 \mathrm{~h}$.

\subsection{Influence of the nature of CNTs}

Two types of CNTs were used for the synthesis of composite materials that are either pure (denoted raw CNTs thereafter) or functionalized (denoted o-CNTs thereafter) CNTs. The later was obtained by treating raw CNTs with nitric acid to oxidize the surface providing additional active sites and functional groups for favor grafting of the inorganic component. Figure 1 presents representative TEM images of the composites containing $5 \mathrm{wt} . \%$ raw CNTs or o-CNTs. It shows that raw CNTs are not effectively covered by nanoparticles that formed separated aggregates (Figure 1a). In contrast, surface functionalization allows nanoparticles to grow on the o-CNTs which are almost fully covered (Figure 1b). High magnification images (Figure 1c,d) better evidences the effective grafting of nanocrystals on the o-CNTs surfaces. The nanoparticles present lattice fringes of $0.350 \mathrm{~nm}$, characteristic to the spacing of (101) planes in anatase. The particle sizes were $\sim 8 \mathrm{~nm}$, consistent with the sample prepared without CNTs. The homogeneity of o-CNTs-based nanocomposites was also confirmed by the recovery of more homogeneous precipitate. 

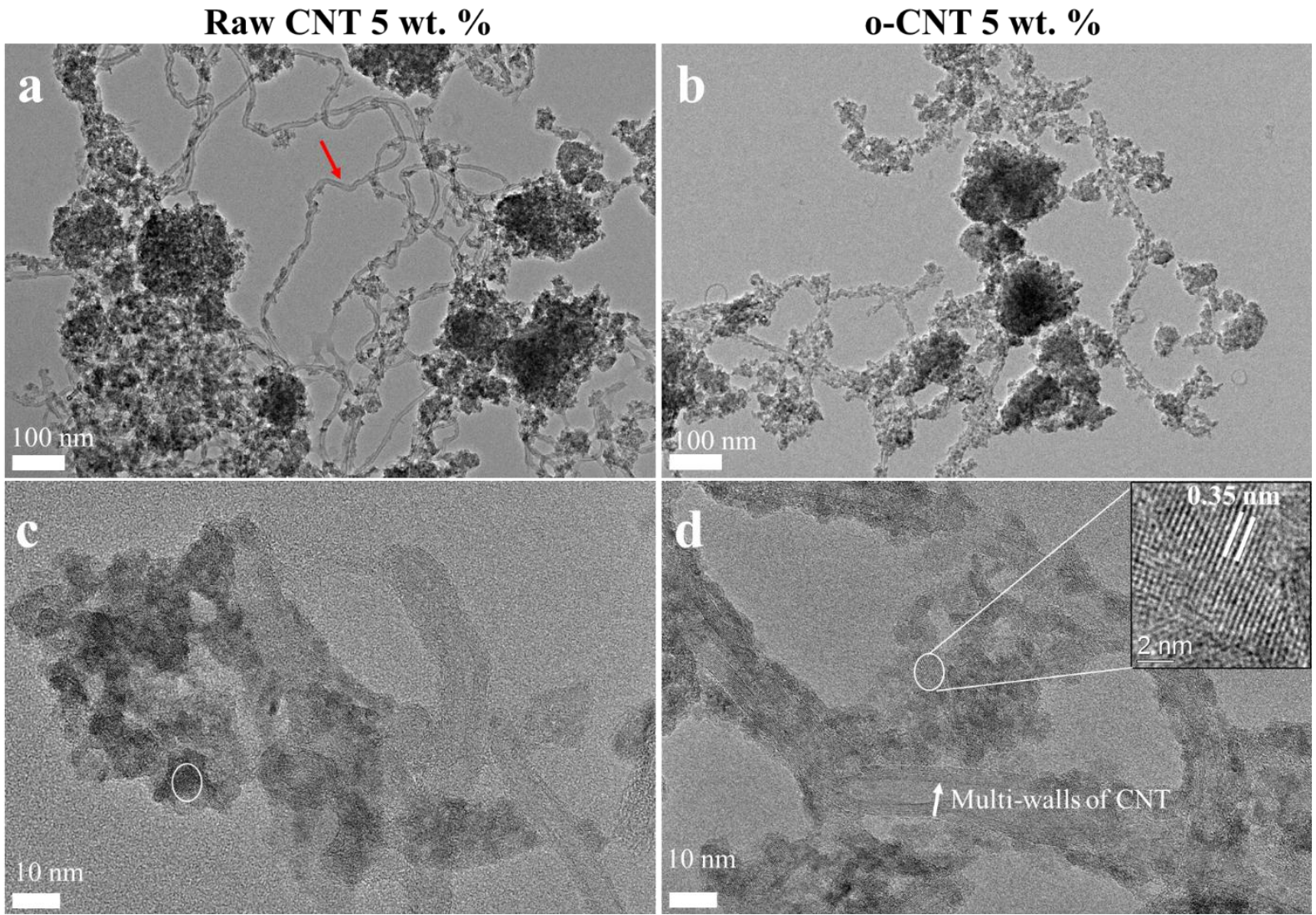

Figure 1: Representative transmission electron microscopy images of composite materials obtained using raw CNTs $(a, c)$ and o-CNTs $(b, d)$. White circles represent single crystals.

\subsection{Influence of the content of $\mathrm{o}-\mathrm{CNTs}$}

The effect of o-CNTs content on the homogeneity of the composite was studied by using two different content of o-CNTs that are 1 and $10 \mathrm{wt} . \%$ (Figure 2). The decrease of the o-CNTs content to $1 \mathrm{wt} . \%$ led to full coverage of o-CNTs by nanoparticles. On the other hand, heavy aggregation of nanoparticles was observed which suggest that $1 \mathrm{wt} . \%$ o-CNTs does not provide sufficient sites for anchoring Ti precursor, so that a large excess of precursors condensed away from o-CNTs. Although TEM is only a qualitative technique, we observed that increasing the o-CNTs content to $10 \mathrm{wt} . \%$ effectively decreases the level of aggregations. Nevertheless, uncovered o-CNTs were observed suggesting that the optimized o-CNTs content lies within 5 to $10 \mathrm{wt} . \%$. 

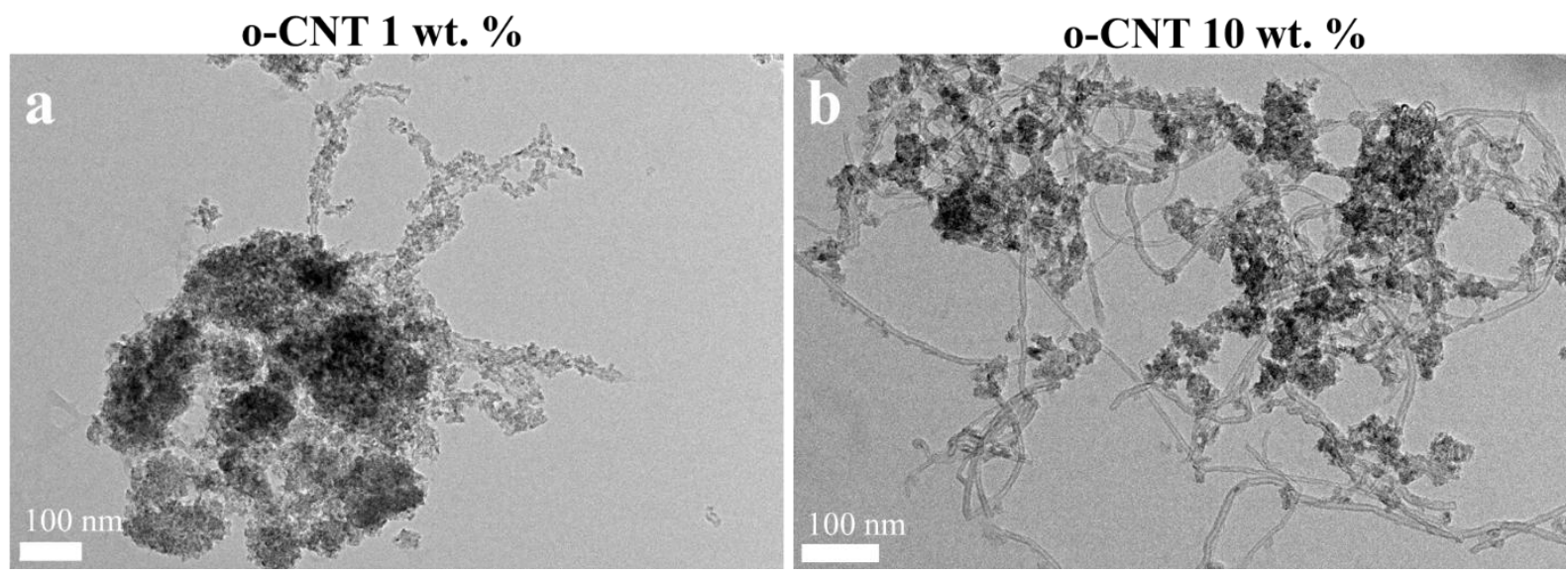

Figure 2: Representative transmission electron microscopy images of composites prepared using $1 \mathrm{wt} . \%$ (a) and $10 \mathrm{wt} . \%$ of o-CNTs.

\subsection{Influence of CNTs on the reactivity of Ti precursor}

X-ray diffraction analysis was performed on the composite prepared using different content of o-CNTs (Figure 3a). All the XRD patterns were indexed with a tetragonal cell (space group I41/amd) characteristic of the anatase type structure. The features of the Bragg peaks in terms of position, intensity remain unchanged whatever the content of o-CNTs, indicating that the presence of o-CNTs did not affect the crystallization of anatase network. The absence of the main (002) line of o-CNTs is due to the weak scattering of carbon.

To further confirm the stabilization of oxy-hydroxyfluorinated anatase, we used the pair distribution function (PDF).[13] The PDF of the composite containing $10 \mathrm{wt} . \%$ of o-CNTs was successfully fitted using the anatase type structural model (Figure 3b). The refined lattice parameters are a = 3.782(1) $\AA$, $\mathrm{c}=9.477(6) \AA$, which is consistent with previous study.[5] The scattering PDF domain was $5 \mathrm{~nm}$ in agreement with TEM observations. Moreover, the refined titanium occupancy was 0.68(3) which is similar to that obtained for the CNTs free compound.[14] The chemical composition assessed by PDF analysis and solid-state ${ }^{19} \mathrm{~F}$ NMR, obtained without carbon additives was indeed determined to be $\mathrm{Ti}_{0.69} \square_{0.31} \mathrm{O}_{0.76} \mathrm{~F}_{0.48}(\mathrm{OH})_{0.76}$, consistent with the vacancy concentration determined here. This further confirms that the presence of CNTs does not affect the formation of fluorinated anatase but in turns provides a support to grow on it. 

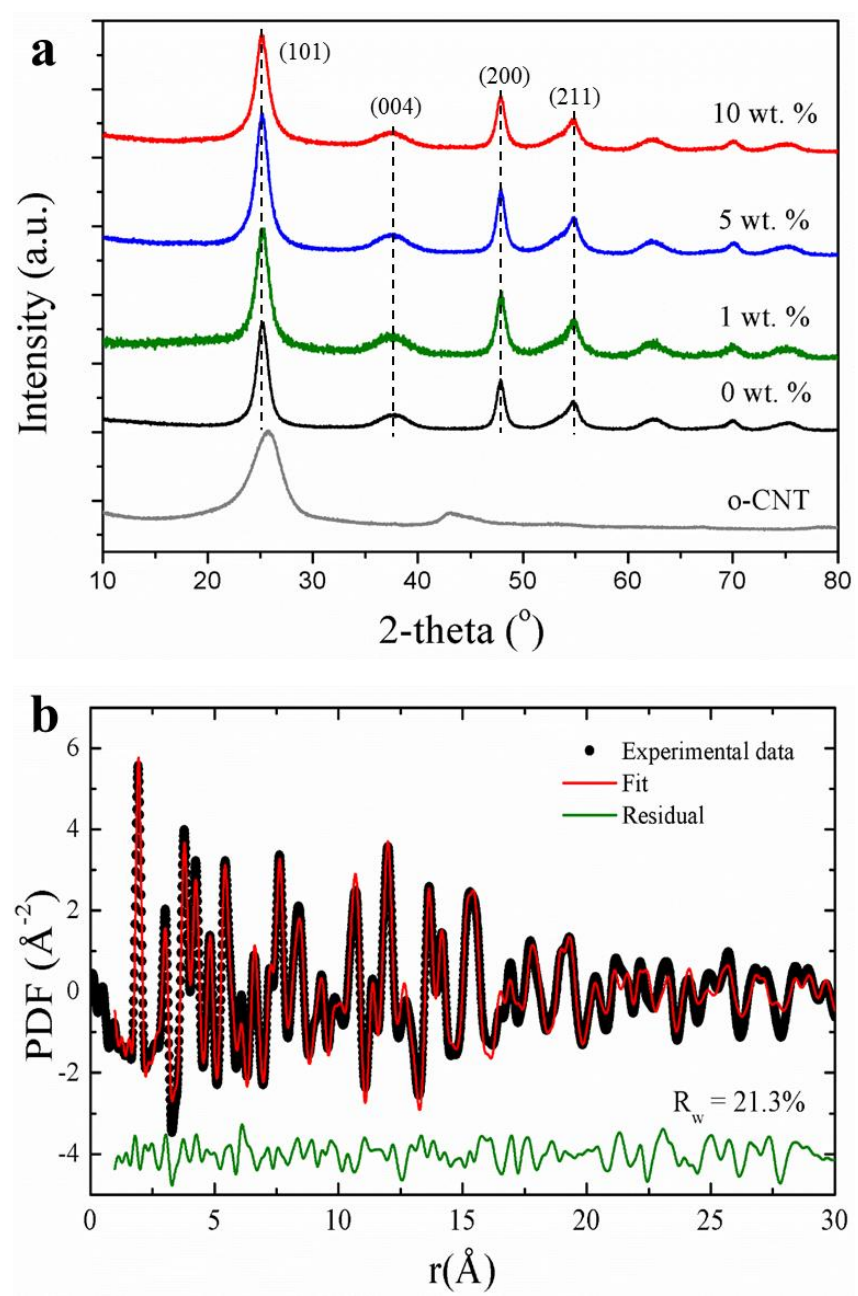

Figure 3: (a) XRD patterns of pristine $\mathrm{Ti}_{0.69} \square_{0.31} \mathrm{O}_{0.76} \mathrm{~F}_{0.48}(\mathrm{OH})_{0.76}$, and composites prepared with different content of o-CNTs. The Bragg peaks of the composites are indexed with anatase type structure. (b) Fit of the PDF data of the composite prepared with $10 \mathrm{wt} . \%$ o-CNTs.

In order to determine whether CNTs can be fluorinated with aqueous HF, a mixture containing oCNTs, HF and isopropanol was treated under the same condition as the composite. Under this condition, the $\mathrm{O}$ content assessed by X-ray photoelectron spectroscopy (XPS) remains similar before and after the treatment. The absence of reactivity of the o-CNTs vs. fluorination was also confirmed by the absence of F1s peak (Figure 4). To check whether titanium alkoxide can alter the reactivity of the o-CNTs vs. fluorine, we further compared the XPS spectrum of a composite containing $10 \mathrm{wt} . \%$ of oCNTs and that of the o-CNTs treated with HF (Figure 4). The presence of o-CNTs did not influence the binding energies of the Ti $2 p$ and F1s peaks.[14] Moreover, the C1s region (Figure 4, inset) was further analyzed to check the formation of any C-F bonds. Table 1 gathers the characteristics of the $\mathrm{C}$ 1s peaks. The $\mathrm{C} 1 \mathrm{~s}$ signals are largely dominated by the $\mathrm{sp}^{2}$-hybridized carbon.[15] In the composite, we observed a $\mathrm{C} 1 \mathrm{~s}$ peak located at $285.84 \mathrm{eV}$ that we assigned to organic residues coming from the sol-gel precursors. The absence of significant peaks at higher binding energies confirms the absence of C-F bonds in the composite.[16,17] 


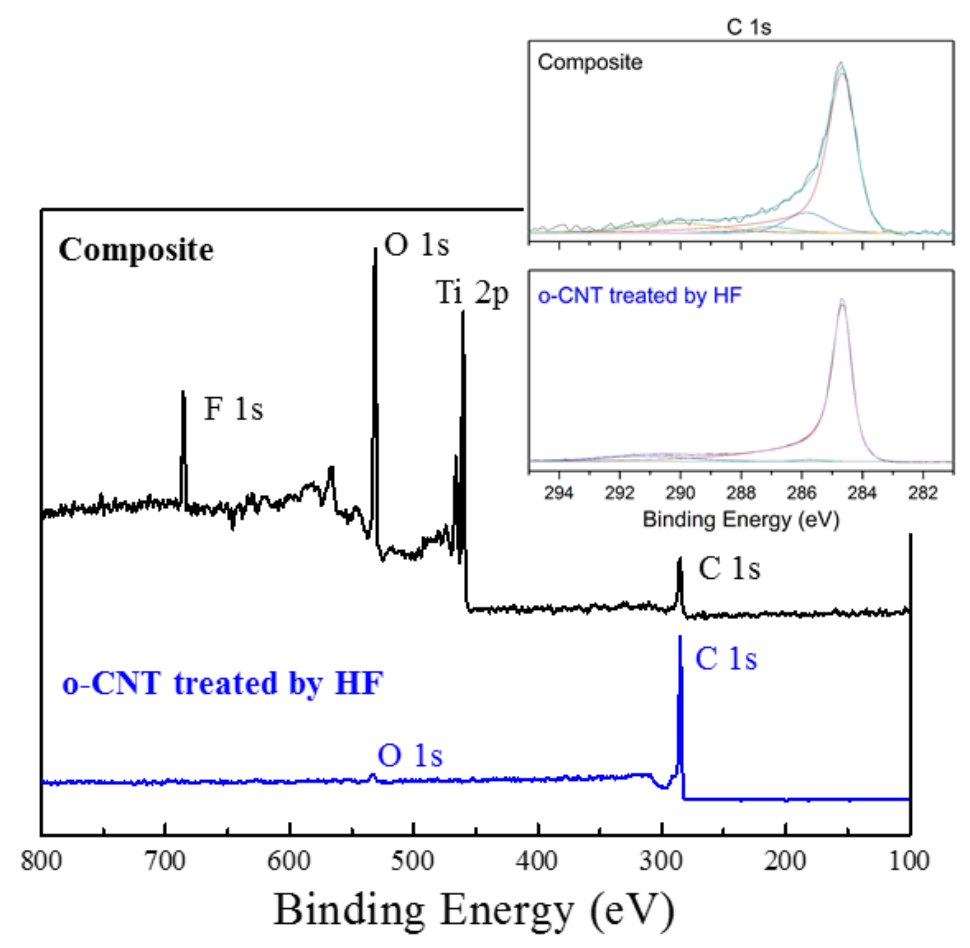

Figure 4: XPS spectra of composite and HF treated o-CNT. Inset: reconstructed C 1s spectra.

\begin{tabular}{|l|l|l|l|l|}
\hline Samples & Assignments & $\begin{array}{l}\text { Peak BE } \\
(\mathbf{e V})\end{array}$ & $\begin{array}{l}\text { FWHM } \\
(\mathbf{e V})\end{array}$ & $\begin{array}{l}\text { Relative intensity } \\
(\boldsymbol{\%})\end{array}$ \\
\hline Composite & C1s sp2 & 284.66 & 1.11 & 74.1 \\
& C1s C-OR & 285.84 & 1.64 & 11.0 \\
& C1s C=O & 287.02 & 1.64 & 3.2 \\
& C1s -O-C=O & 288.16 & 1.64 & 1.1 \\
& C1s Satellite & 290.07 & 3.37 & 10.6 \\
\hline \multirow{2}{*}{ o-CNT treated } & C1s sp2 & 284.66 & 0.75 & 90.0 \\
with HF & C1s C-OR & 285.84 & 0.98 & 0.9 \\
& C1s satellite & 287.02 & 3.37 & 9.1 \\
\hline
\end{tabular}

Table 1. Assignments and binding energy of $\mathrm{C} 1 \mathrm{~s}$ peaks of the composite and o-CNT treated with HF.

\section{Conclusions}

In summary, we synthesized composite materials with CNTs and anatase nanoparticles using a sol-gel process performed in the presence of aqueous HF. Our results showed that CNTs are inactive toward fluorination. On the other hand, titanium isopropoxide reacts via fluoro/hydrolysis reactions to form oxy-hydroxyfluorinated anatase. Of importance is the surface state of the CNTs, with oxidized surface providing sites for nucleation-growth of anatase nanoparticles. As a result, a composite material featuring CNTs decorated by nanocrystals was obtained. This study proves that other fluorinated inorganic compounds could be integrated on carbon substrates to tune material's properties with respect to the targeted applications.

\section{Experimental}




\section{Materials synthesis:}

Multiwalled carbon nanotubes (CNT) were obtained from Arkema (CCVD, Groupement de Recherches de Lacq, Arkema) with a carbon purity of more than 90wt\%. These CNTs are composed of 5 to 15 walls with an outer diameter from few $\mathrm{nm}$ to $20 \mathrm{~nm}$ and a length ranging from 0.1 to $10 \mu \mathrm{m}$. To obtain oxidized CNTs (o-CNTs), $2 \mathrm{~g}$ of CNTs were stirred in $60 \mathrm{~mL}$ solution of $\mathrm{HNO}_{3} 10 \mathrm{~mol} \mathrm{~L}^{-1}$ at $80^{\circ} \mathrm{C}$ during 4 hours. Subsequently, o-CNTs was extensively washed with water and dried overnight at $120^{\circ} \mathrm{C}$.

The synthesis of CNT-anatase composite was performed using a modified protocol found in reference [5]. A defined amount of CNTs was firstly suspended in $14.8 \mathrm{~mL}$ isopropanol inside a Teflon-lined cup. The resulting mixture was sonicated for $1 \mathrm{~h}$ to favor the CNTs dispersion. Thereafter $4 \mathrm{~mL}$ of titanium isopropoxide was added and the mixture was stirred vigorously for $30 \mathrm{~min}$. A solution of 10 $\mathrm{mL}$ isopropanol containing $1.2 \mathrm{~mL}$ aqueous $\mathrm{HF}$ (40 wt.\%) was subsequently poured into the system under stirring. The mixture was sealed in a stainless steel autoclave and activated solvothermally at $90{ }^{\circ} \mathrm{C}$ for $12 \mathrm{~h}$. After cooling down to room temperature, the precipitate was separated from the solution using centrifugation (4400 rpm) and washed three times with ethanol. The solid was finally dried at $80{ }^{\circ} \mathrm{C}$ for $2 \mathrm{~h}$.

Material characterization: Powder X-ray diffraction data were collected using a Rikaku diffractometer, equipped with $\mathrm{Cu} \mathrm{K} \alpha$ radiation, in a Bragg-Brentano geometry. The Transmission Electron Microscopy analysis was performed using a JEOL 2010 UHR microscope operating at 200 $\mathrm{kV}$ equipped with a TCD camera.

Total scattering data were collected at the 11-ID-B beamline at the Advanced Photon Source at Argonne National Laboratory, using high energy X-rays $(\lambda=0.2128 \AA)$ with high values of momentum transfer $\mathrm{Qmax}=22 \AA^{-1} .[18,19]$ One-dimensional diffraction data were obtained by integrating the raw 2D total scattering data in Fit2D.[20] PDFs, G(r), were extracted from the background and Compton scattering corrected data following Fourier transform within PDFgetX2.[21] The PDFs were subsequently modeled using PDFgui.[22]

X-ray photoelectron spectroscopy (XPS) was performed using a VG ESCALAB 250 spectrometer with an $\mathrm{Al} \mathrm{K \alpha}$ monochromatic source $(15 \mathrm{kV}, 15 \mathrm{~mA})$ and a multidetection analyzer, under $10^{-8} \mathrm{~Pa}$ residual pressure.

\section{Acknowledgements}

We thank S. Casale for HRTEM analyses. The work done at the Advanced Photon Source, an Office of Science User Facility operated for the U.S. Department of Energy (DOE) Office of Science by Argonne National Laboratory, was supported by the U.S. DOE under Contract No. DE-AC02$06 \mathrm{CH} 11357$. 


\section{References}

[1] J. Livage, M. Henry, C. Sanchez, Sol-gel chemistry of transition metal oxides, Prog. Solid State Chem. 18 (1988) 259-341. doi:10.1016/0079-6786(88)90005-2.

[2] E. Kemnitz, U. Groß, S. Rüdiger, C.S. Shekar, Amorphous Metal Fluorides with Extraordinary High Surface Areas, Angew. Chem. Int. Ed. 42 (2003) 4251-4254. doi:10.1002/anie.200351278.

[3] S. Rüdiger, E. Kemnitz, The fluorolytic sol-gel route to metal fluorides-a versatile process opening a variety of application fields, Dalton Trans. (2008) 1117-1127. doi:10.1039/B716483A.

[4] H.G. Yang, C.H. Sun, S.Z. Qiao, J. Zou, G. Liu, S.C. Smith, H.M. Cheng, G.Q. Lu, Anatase $\mathrm{TiO} 2$ single crystals with a large percentage of reactive facets, Nature. 453 (2008) 638-641. doi:10.1038/nature06964.

[5] W. Li, D. Corradini, M. Body, C. Legein, M. Salanne, J. Ma, K.W. Chapman, P.J. Chupas, A.-L. Rollet, C. Julien, K. Zhagib, M. Duttine, A. Demourgues, H. Groult, D. Dambournet, High Substitution Rate in TiO2 Anatase Nanoparticles with Cationic Vacancies for Fast Lithium Storage, Chem. Mater. 27 (2015) 5014-5019. doi:10.1021/acs.chemmater.5b01407.

[6] W. Li, M. Body, C. Legein, O.J. Borkiewicz, D. Dambournet, Atomic Insights into Nanoparticle Formation of Hydroxyfluorinated Anatase Featuring Titanium Vacancies, Inorg. Chem. 55 (2016) 7182-7187. doi:10.1021/acs.inorgchem.6b01259.

[7] X. Dang, H. Yi, M.-H. Ham, J. Qi, D.S. Yun, R. Ladewski, M.S. Strano, P.T. Hammond, A.M. Belcher, Virus-templated self-assembled single-walled carbon nanotubes for highly efficient electron collection in photovoltaic devices, Nat. Nanotechnol. 6 (2011) 377-384. doi:10.1038/nnano.2011.50.

[8] B. Liu, H.C. Zeng, Carbon Nanotubes Supported Mesoporous Mesocrystals of Anatase TiO2, Chem. Mater. 20 (2008) 2711-2718. doi:10.1021/cm800040k.

[9] L. Kavan, R. Bacsa, M. Tunckol, P. Serp, S.M. Zakeeruddin, F. Le Formal, M. Zukalova, M. Graetzel, Multi-walled carbon nanotubes functionalized by carboxylic groups: Activation of $\mathrm{TiO} 2$ (anatase) and phosphate olivines (LiMnPO4; LiFePO4) for electrochemical Li-storage, J. Power Sources. 195 (2010) 5360-5369. doi:10.1016/j.jpowsour.2010.03.028.

[10] X. Peng, J. Chen, J.A. Misewich, S.S. Wong, Carbon nanotube-nanocrystal heterostructures, Chem. Soc. Rev. 38 (2009) 1076-1098. doi:10.1039/B811424M.

[11] T. Koketsu, J. Ma, B.J. Morgan, M. Body, C. Legein, W. Dachraoui, M. Giannini, A. Demortière, M. Salanne, F. Dardoize, H. Groult, O.J. Borkiewicz, K.W. Chapman, P. Strasser, D.

Dambournet, Reversible magnesium and aluminium ions insertion in cation-deficient anatase $\mathrm{TiO}_{2}$, Nat. Mater. 16 (2017) 1142. doi:10.1038/nmat4976.

[12] D.O. Scanlon, C.W. Dunnill, J. Buckeridge, S.A. Shevlin, A.J. Logsdail, S.M. Woodley, C.R.A. Catlow, M.J. Powell, R.G. Palgrave, I.P. Parkin, G.W. Watson, T.W. Keal, P. Sherwood, A. Walsh, A.A. Sokol, Band alignment of rutile and anatase $\mathrm{TiO}_{2}$, Nat. Mater. 12 (2013) 798-801. doi:10.1038/nmat3697.

[13] S.J.L. Billinge, M.G. Kanatzidis, Beyond crystallography: the study of disorder, nanocrystallinity and crystallographically challenged materials with pair distribution functions, Chem. Commun. (2004) 749-760. doi:10.1039/b309577k. 
[14] J. Ma, W. Li, B.J. Morgan, J. Światowska, R. Baddour-Hadjean, M. Body, C. Legein, O.J. Borkiewicz, S. Leclerc, H. Groult, F. Lantelme, C. Laberty-Robert, D. Dambournet, Lithium Intercalation in Anatase Titanium Vacancies and the Role of Local Anionic Environment, Chem. Mater. 30 (2018) 3078-3089. doi:10.1021/acs.chemmater.8b00925.

[15] J.-M. Lee, S.J. Kim, J.W. Kim, P.H. Kang, Y.C. Nho, Y.-S. Lee, A high resolution XPS study of sidewall functionalized MWCNTs by fluorination, J. Ind. Eng. Chem. 15 (2009) 66-71. doi:10.1016/j.jiec.2008.08.010.

[16] A. Tressaud, F. Moguet, S. Flandrois, M. Chambon, C. Guimon, G. Nanse, E. Papirer, V. Gupta, O.P. Bahl, On the nature of $\mathrm{C} \square \mathrm{F}$ bonds in various fluorinated carbon materials: XPS and TEM investigations, J. Phys. Chem. Solids. 57 (1996) 745-751. doi:10.1016/0022-3697(96)00343-5.

[17] M. Herraiz, M. Dubois, N. Batisse, S. Hajjar-Garreau, L. Simon, Large-scale synthesis of fluorinated graphene by rapid thermal exfoliation of highly fluorinated graphite, Dalton Trans. 47 (2018) 4596-4606. doi:10.1039/C7DT04565D.

[18] P.J. Chupas, K.W. Chapman, P.L. Lee, Applications of an amorphous silicon-based area detector for high-resolution, high-sensitivity and fast time-resolved pair distribution function measurements, J. Appl. Crystallogr. 40 (2007) 463-470. doi:10.1107/S0021889807007856.

[19] P.J. Chupas, X. Qiu, J.C. Hanson, P.L. Lee, C.P. Grey, S.J.L. Billinge, Rapid-acquisition pair distribution function (RA-PDF) analysis, J. Appl. Crystallogr. 36 (2003) 1342-1347. doi:10.1107/S0021889803017564.

[20] A.P. Hammersley, S.O. Svensson, M. Hanfland, A.N. Fitch, D. Hausermann, Two-dimensional detector software: From real detector to idealised image or two-theta scan, High Press. Res. 14 (1996) 235-248. doi:10.1080/08957959608201408.

[21] X. Qiu, J.W. Thompson, S.J.L. Billinge, PDFgetX2: a GUI-driven program to obtain the pair distribution function from X-ray powder diffraction data, J. Appl. Crystallogr. 37 (2004) 678678. doi:10.1107/S0021889804011744.

[22] C.L. Farrow, P. Juhas, J.W. Liu, D. Bryndin, E.S. Božin, J. Bloch, T. Proffen, S.J.L. Billinge, PDFfit2 and PDFgui: computer programs for studying nanostructure in crystals, J. Phys. Condens. Matter. 19 (2007) 335219. doi:10.1088/0953-8984/19/33/335219. 